\title{
Ruthenium organometallic compounds as ABC drug efflux-targeted agents and collateral sensitizers
}

Ricardo G. Teixeira ${ }^{1,2}$, Dimas C. Belisario ${ }^{3}$, Ana Isabel Tomaz ${ }^{1,2}$, M. Helena Garcia $^{1,2}$, Chiara Riganti3, Andreia Valente ${ }^{1,2}$

${ }^{1}$ Centro de Química Estrutural, Faculdade de Ciências, Universidade de Lisboa, Campo Grande, 1749-016 Lisboa, Portugal. 2 Departamento de Química e Bioquímica, Faculdade de Ciências, Universidade de Lisboa, Campo Grande, $1749-016$ Lisboa, Portugal. Department of Oncology, University of Torino, Italy.

\section{BACKGROUND}

Our research group has been focused on exploring metal-based compounds, especially incorporating the "ruthenium-cyclopentadienyl" ("RuCp") scaffold.[1] This moiety is an appealing and robust scaffold to build new molecules from where the judicious choice of co-ligands allows to impart different properties and to fine-tune the performance of the whole complex.

In this frame, we developed new compounds based on the functionalized "RuCp" moiety containing bipyridyl ligands which were tested against four non-small cell lung cancer (NSCLC) cell lines: A549, NCl-H228, Calu-3 and NClH1975. Our preliminary results show that the compounds are more cytotoxic in cisplatin-resistant than in cisplatin-sensitive cells, and increased cisplatin cytotoxicity by inhibiting MRP1 and P-gp transporters. This work unveils the mechanism of action of these compounds, suggesting that drug efflux transporters could be a potential target, and, more importantly, indicates that they induce collateral sensitivity in cisplatinresistant lung cancer cells.

\section{RESULTS}

\section{Synthesis}

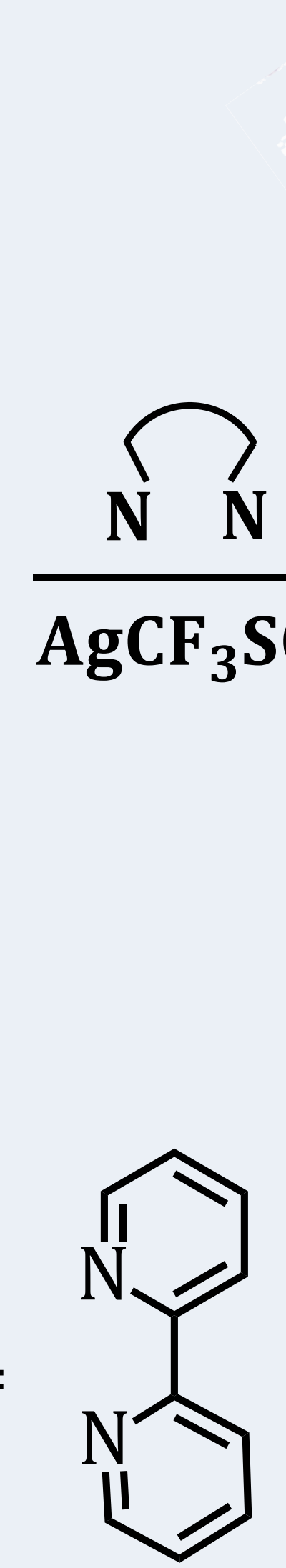

$(1, \underline{5})$<smiles></smiles>

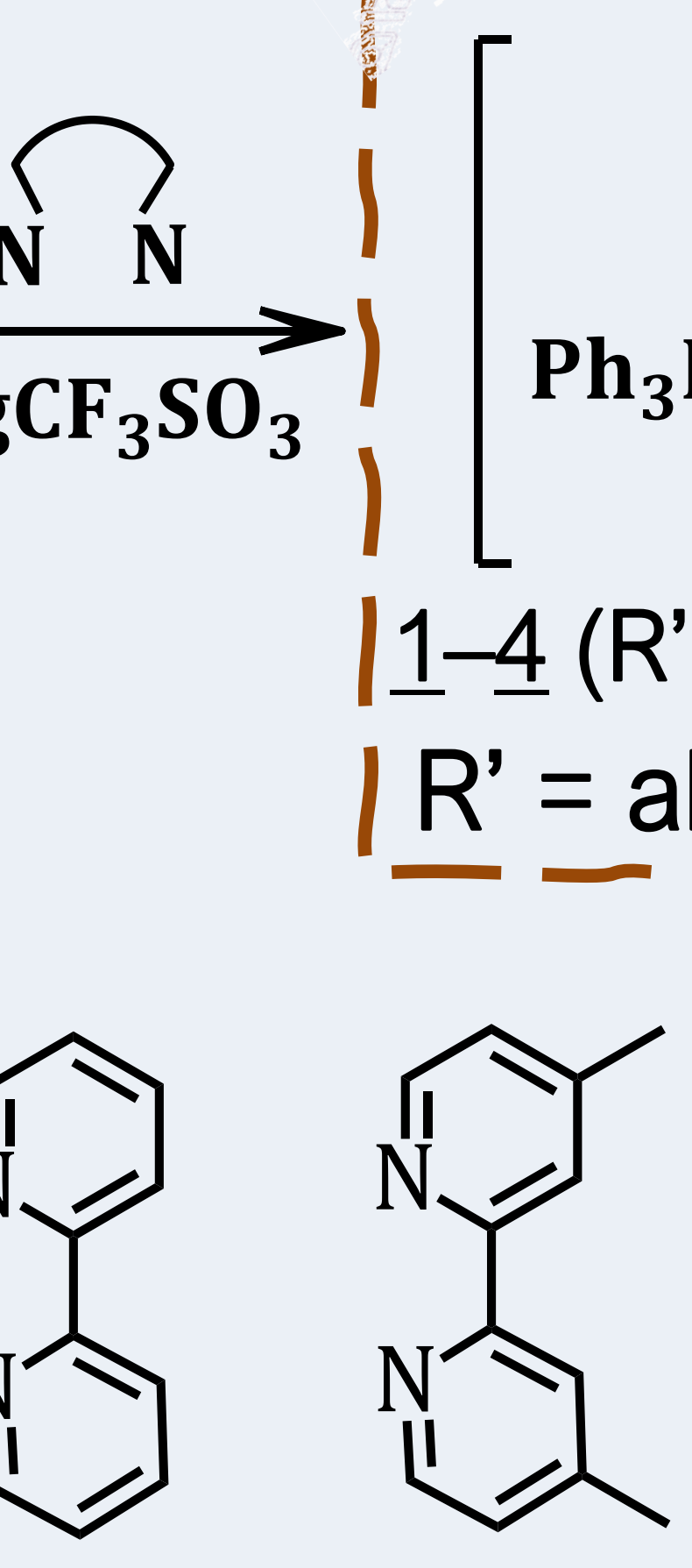

$(\underline{2}, \underline{6})$<smiles></smiles>

$(\underline{3}, \underline{7})$ 2 - 'Chemistry-on-the-complex' reaction

$\mathbf{P h}_{3} \mathbf{P}^{\prime \mathbf{R u}^{\prime} \mathbf{P h}_{3}}$
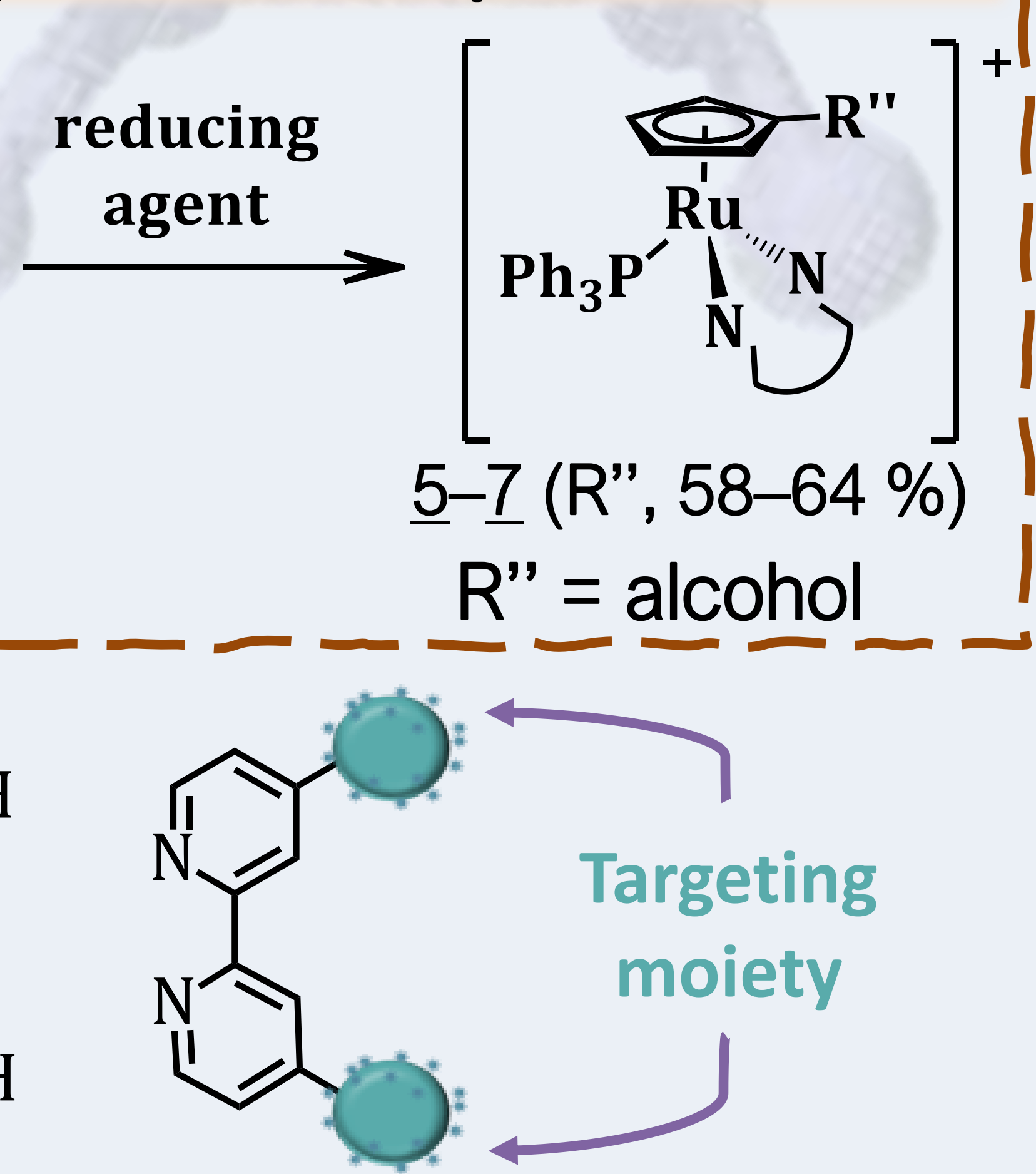

(4)
- Seven new compounds were synthesized and characterized by several spectroscopic techniques

- Crystallographic studies confirmed the proposed 'piano-stool' geometry

- All compounds are stable in aqueous solutions over $24 \mathrm{~h}$

\section{In vitro screening in NSCLC}

Table 1. $I C_{50}(\mu \mathrm{M})$ of the new ruthenium compounds and cisplatin in the cell lines analyzed after $72 \mathrm{~h}$ of incubation.

$\begin{array}{lccccc} & \underline{1} & \underline{2} & \underline{4} & \underline{6} & \text { Cisplatin } \\ \text { A549 } & 10.8 \pm 1.3 & 12.4 \pm 3.6 & 15.4 \pm 2.6 & 12.5 \pm 2.1 & >100 \\ \text { NCl-H228 } & 4.3 \pm 0.7 & 3.8 \pm 1.4 & 16.5 \pm 1.3 & 7.8 \pm 1.2 & >100 \\ \text { Calu-3 } & 24.7 \pm 4.1 & 4.9 \pm 1.6 & 28.9 \pm 0.8 & 5.9 \pm 1.2 & 63.4 \pm 8.7 \\ \text { NCl-H1975 } & 91.8 \pm 10.4 & >100 & >100 & >100 & 3.8 \pm 1.1\end{array}$

- Compounds $\underline{1}, \underline{2}, \underline{4}$ and $\underline{6}$ show strong activity against cisplatinresistant NSCLC A549 and $\mathrm{NCl}-\mathrm{H} 228$

- Compounds $\underline{3}, \underline{5}$ and $\underline{7}$ were inactive in the cell lines studied

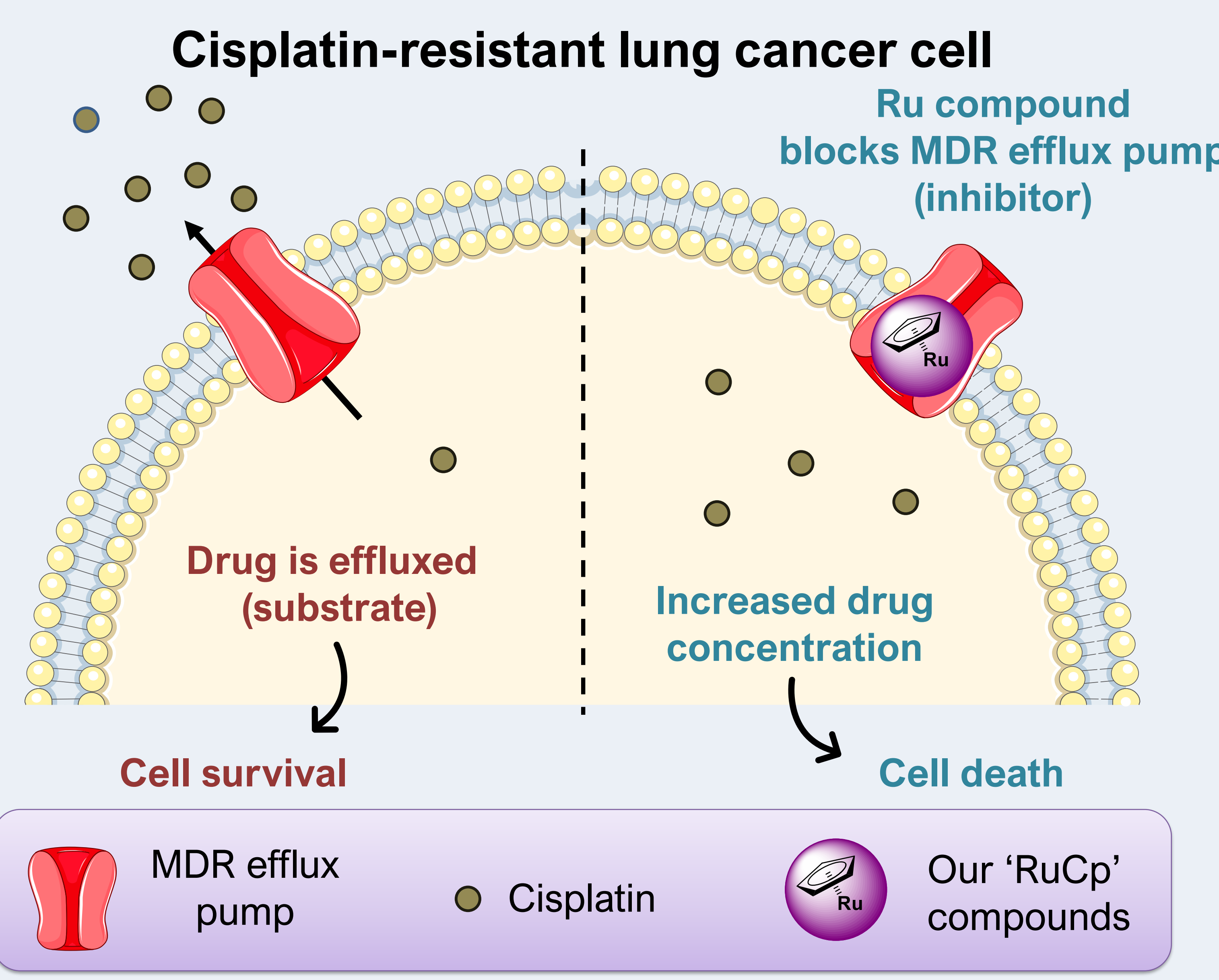

\section{Collateral sensitivity}

Table 2. Resistance factor $\left(\mathrm{Rf}=I \mathrm{C}_{50}\right.$ (cisplatin) $/ I \mathrm{C}_{50}$ (cisplatin $+I \mathrm{I}_{25}$ Compound $\left.)\right)$ of the cell lines treated with cisplatin versus cisplatin and Ru compounds.

\begin{tabular}{|lcccc|}
\hline & $\underline{1}$ & $\underline{2}$ & $\underline{4}$ & $\underline{6}$ \\
\hline A549 & 71.4 & 555.6 & 1250 & 243.9 \\
\hline NCl-H228 & 333.3 & 1389.9 & 588.2 & 344.8 \\
\hline Calu-3 & 26.3 & 126 & 33.2 & 78.7 \\
\hline NCl-H1975 & 2.9 & 0.6 & 1.6 & 0.7 \\
\hline
\end{tabular}

- The selected compounds were able to increase cisplatin cytotoxicity (up to 1390-fold) when administrated at nontoxic doses

\section{Inhibition of ABC transporters}

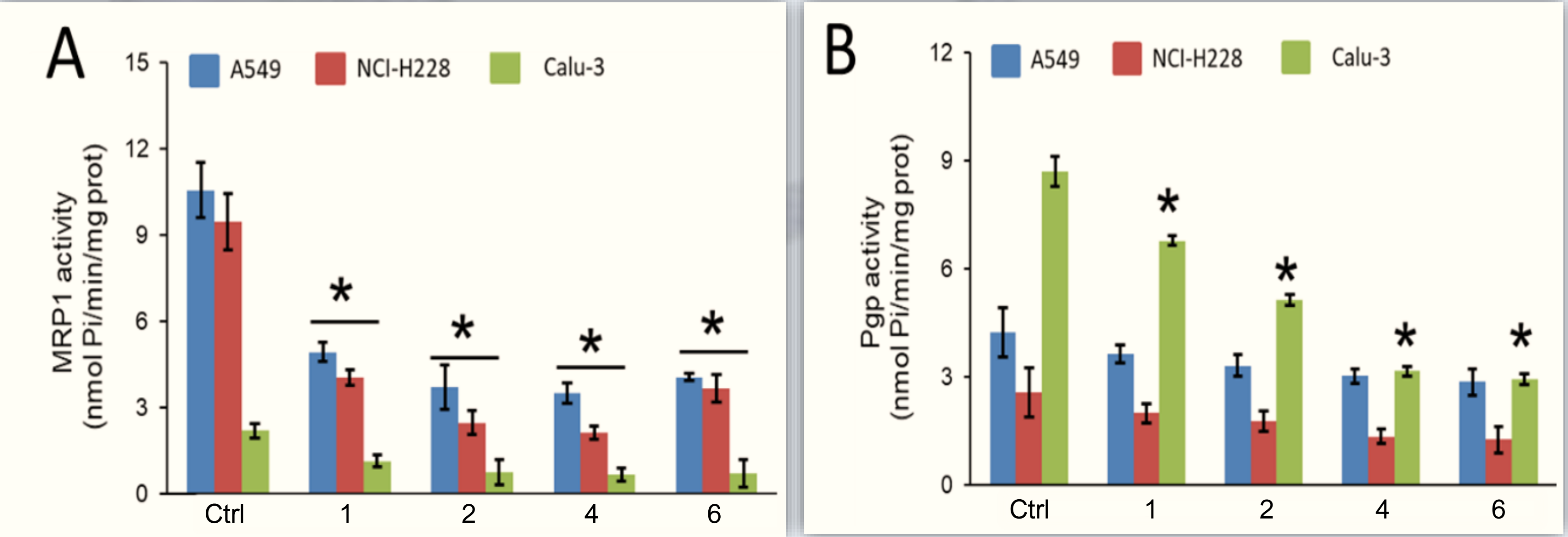

Figure 1. MRP1 (A) and P-gp (B) ATPase activity measured on the proteins immune-purified from cells treated without (ctrl) or with $1 \mu \mathrm{M}$ of compounds $\underline{1}, \underline{2}, \underline{4}$ and $\underline{6}$ for $24 \mathrm{~h}$.

- Compounds $\underline{1}, \underline{2}, \underline{4}$ and $\underline{6}$ inhibited MRP1 and P-gp activity in A549, $\mathrm{NCl}-\mathrm{H} 228$ and Calu-3 cell lines, which overexpress these transporters.

\section{CONCLUSIONS}

- Seven new 'RuCp' compounds were successfully synthesized and characterized

- Compounds $\underline{1}, \underline{2}, \underline{4}$ and $\underline{6}$ were cytotoxic against NSCLC cell lines

- Our compounds increased the sensitivity to cisplatin in the resistant cell lines by inhibiting MRP1 and P-gp transporters 